\title{
O Twitter como ferramenta de campanha negativa não oficial: uma análise da campanha eleitoral para a Prefeitura do Rio de Janeiro em 2016
}

\author{
Ícaro Joathan' \\ https://orcid.org/0000-0002-3917-8346 \\ Marcelo Alves' \\ https://orcid.org/0000-0003-4995-6612 \\ I - Universidade Federal Fluminense \\ Rio de Janeiro (RJ), Brasil
}

Resumo: Analisar a adoção da estratégia de campanha negativa não oficial no Twitter na disputa pela Prefeitura do Rio de Janeiro em 2016 é o objetivo deste artigo. Esse fenômeno, caracterizado pela promoção de ataques em períodos eleitorais por grupos independentes das coligações oficiais, é pouco estudado na literatura brasileira. A fim de ajudar a preencher essa lacuna, analisam-se as mensagens postadas no microblog durante o segundo turno do aludido pleito por eleitores e redes de apoio e ataque aos principais candidatos Marcelo Crivella (PRB) e Marcelo Freixo (PSOL). A metodologia usa técnicas de análise de conteúdo, análise de redes sociais e análise estatística de um corpus inicial de 530 mil tweets coletados por meio da Twitter Search API, resultando em uma amostra final de 11.407 postagens classificadas como negativas. Entre as conclusões é possível afirmar que os principais agentes de campanha negativa não oficial no Twitter apresentam funções e perfis distintos, podendo ser divididos entre os influenciadores e os disseminadores de publicações de ataque.

Palavras-chave: comunicação política; Twitter; campanha negativa; análise de redes sociais.

Abstract: Twitter as a tool of unofficial negative campaign: an analysis of the $\mathbf{2 0 1 6}$ mayoral election campaign in Rio de Janeiro - This paper analyzes the dissemination of an unofficial negative campaign on Twitter, during the 2016 mayoral election campaign in Rio de Janeiro. The sponsorship of attack messages in electoral races by groups not officially linked to parties and candidates is a strategy little studied in Brazil. To fill this gap, we analyzed the messages posted on Twitter during the second round of that election by the partisans from the main candidates 
Marcelo Crivella (PRB) and Marcelo Freixo (PSOL), as well as by networks supporting and attacking them. The methodology includes Content Analysis, Social Network Analysis and statistical analysis of an initial sample of 530,000 tweets gathered through Twitter Search API, reaching a final sample of 11,407 posts classified as negative. The results show that the main negative campaign agents have different roles and profiles on Twitter, being identified as influencers or disseminators of attack contents.

Keywords: political communication; Twitter; negative campaign; social network analysis.

\section{Introdução}

A campanha negativa é uma estratégia de comunicação política que passou a influenciar de forma relevante os processos eleitorais nos Estados Unidos a partir da década de 1950. Desde os anos 80, a veiculação de ataques eleitorais por grupos não oficiais - sem ligações oficiais com os partidos e seus respectivos candidatos - também começou a ser estudada entre os pesquisadores norte-americanos (GARRAMONE, 1985).

Esses agrupamentos não oficiais que veiculam propaganda eleitoral nos Estados Unidos são denominados de diversas formas, entre as quais grupos independentes, grupos de terceiro partido, grupos de fora, grupos desconhecidos, grupos apartidários e grupos de interesse (BAUMGARTNER, 2013; CHENG \& RIFFE, 2008; DALTON \& MCILWAIN, 2011; DOWLING \& WITCHOWSKY, 2015).

No Brasil, há pesquisas sobre a participação de coletivos de apoio a candidatos em processos eleitorais antes até da popularização da internet, com foco na descentralização da difusão de informações políticas, pelas quais os próprios eleitores contribuem para a propagação das mensagens (QUELER, 2010). Contudo, esse fenômeno foi modificado e ganhou relevância com o surgimento e o crescimento das mídias sociais, as quais tiveram uma primeira influência notável no pleito de 2010, a partir de quando os candidatos passaram a negociar a construção da própria imagem e a ocupação de espaços na esfera pública com outros atores (CERVI \& MASSUCHIN, 2011).

Alves (2017a) sugere o conceito de campanha não oficial para definir a sistematização da criação e veiculação de conteúdos políticos por redes que atacam ou defendem candidatos na web, às quais não são diretamente ligadas às coligações oficiais, porém não trata especificamente da problemática da campanha negativa. O fenômeno tem ganhado relevância devido a sua influência nos pleitos brasileiros de 2014, 2016 e $2018^{1}$ (ALVES, 2017a; ÁRNAUDO, 2017), e, no contexto internacional, pela influência de agentes não ligados oficialmente a partidos no pleito presidencial de 2016 nos Estados Unidos (ALCOTT; \& GENTZKOW, 2017; PERSILY, 2017).

Considerando a escassa literatura sobre campanha negativa não oficial no Brasil, o reduzido quantitativo de trabalhos sobre o uso dessa estratégia na web mesmo

1 Ver https://www.correio24horas.com.br/noticia/nid/as-redes-que-balancam-as-eleicoes-internet-revolucionacenario-da-disputa-no-pais/ (acesso em 23/12/2018). 
no exterior ${ }^{2}$, bem como a relevância e a atualidade do tema - demonstradas acima - este artigo investiga a adoção da estratégia de campanha negativa não oficial no Twitter durante o $2^{\circ}$ turno do pleito de 2016 para prefeito do Rio de Janeiro, com foco em analisar o papel desempenhado pelas redes de ataque aos candidatos Marcelo Crivella (PRB) e Marcelo Freixo (PSOL), que polarizaram a disputa e mobilizaram militantes e simpatizantes.

Para isso, buscamos responder às seguintes questões de pesquisa (QPs): 1) Como identificar as características da campanha negativa não oficial no Twitter?; 2) Qual a estrutura topológica das redes que atacam os candidatos nesta mídia social?; e 3) Como podem ser caracterizados os principais perfis que veicularam campanha negativa não oficial no Twitter durante o período analisado?

Para chegar a essas respostas, as metodologias utilizadas são a Análise de Redes Sociais, a análise de conteúdo e a análise estatística, por meio de amostra composta inicialmente por 530 mil tweets coletados durante o $2^{\circ}$ turno do pleito municipal do Rio em 2016, dos quais classificamos 11.407 tweets como sendo de ataque a, pelo menos, um dos dois candidatos (ou ambos). A seção metodológica deste artigo detalhará como foi coletada e analisada a amostra. A seguir, serão discutidos os aspectos teóricos sobre campanha negativa e campanha não oficial que embasam esta pesquisa.

\section{A campanha negativa}

A campanha negativa é uma estratégia de comunicação eleitoral que começou a ganhar destaque nos Estados Unidos no contexto do movimento de profissionalização das campanhas, a partir da década de 1950, e consiste na difusão de conteúdos negativos contra candidatos ou partidos rivais. Ao recorrer a esse artifício, as coligações podem ter objetivos diversos, sendo um dos principais tentar reverter desvantagem em pesquisas de intenção de votos (ANSOLABEHERE \& IYENGAR, 1995; BORBA, 2012).

Contudo, a campanha negativa também apresenta riscos a candidatos e partidos que a adotam. Um dos problemas mais estudados é o efeito bumerangue, processo resultante da má avaliação pelo público do ataque patrocinado por um dos candidatos, o que resulta em perda de votos para quem atacou (BAUMGARTNER, 2013; CHENG \& RIFFE, 2008; GARRAMONE, 1985).

Nesse contexto, contar com a atuação de agrupamentos independentes para promover campanha negativa passou a ser uma alternativa aos candidatos norte-americanos para diminuir os riscos do efeito bumerangue. A veiculação de ataques por grupos não oficiais pode ampliar os efeitos negativos sobre o rival e dirimir efeitos reversos para o candidato

2 Em um banco de 211 artigos sobre campanha negativa catalogados continuamente desde 2014 por meio de consulta ao Portal de Periódicos da Capes (ver www.periodicos.capes.gov.br), ao Scopus (www.scopus.com) e ao Google Acadêmico (www.scholar.google.com.br), só 5\% tratam de campanha negativa não oficial na web. A grande maioria foca na veiculação de ataques provenientes de candidatos e/ou partidos. Ver revisão de literatura na seção 2 . 
apoiado por esses coletivos (DOWLING \& WITCHOWSKY, 2015; GARRAMONE, 1985), mas esse potencial não é consenso na literatura: Meirick (2005), por exemplo, verificou efeito oposto.

Esses agrupamentos podem ser definidos como coletivos não diretamente ligados a um candidato ou partido e regulados pela legislação norte-americana (DOWLING \& WITCHOWSKY, 2015), mas que integram juntos com estes uma rede partidária mais ampla:

Vários atores dessas redes partidárias se envolvem em estilo compensatório de cooperação, dividindo o trabalho da publicidade de ataque (...) Essa divisão do trabalho permite que os candidatos reduzam ataques que carregam o risco do efeito bumerangue do público (MILLER, 2016, p. 2).

Para além dos EUA, há poucas pesquisas relacionadas à campanha negativa não oficial, caso do pleito presidencial romeno de 2004, quando foram postados conteúdos de ataque por fontes desconhecidas (MOMOC, 2010), e da campanha para presidente da França, em 2012, na qual foram identificados vídeos de afronta a candidatos em canais não oficiais no YouTube (DE BOER \& SÜTFELD; GROSHEK, 2012). Em 2004, no Brasil, eleitores postaram ataques contra postulantes à Prefeitura de São Paulo na extinta rede social Orkut, fato que se repetiu na corrida presidencial de 2006, como verificou Chaia (2007), porém em pesquisa focada na propaganda oficial.

Alves (2017a) mostrou como funcionaram as redes de ataque aos candidatos no Facebook na eleição presidencial brasileira de 2014, porém não correlacionou o fenômeno à questão da campanha negativa. Nesse mesmo pleito, Joathan e Marques (2017) aferiram que Aécio Neves (PSDB) e Dilma Rousseff (PT) compartilharam conteúdo negativo publicado por políticos, celebridades e eleitores comuns na mesma rede social, mas se ativeram às fanpages oficiais.

Mesmo nos Estados Unidos, há poucos estudos circunscritos à internet sobre a campanha negativa não oficial. A maioria foca na publicidade televisiva (CHENG \& RIFFE, 2008; DALTON \& MCILWAIN, 2011; GARRAMONE, 1985; MILLER, 2016). Alguns dos poucos trabalhos sobre ataques postados por grupos não oficialmente partidários na internet são os de Devlin (2005), segundo o qual grupos de apoio ao democrata John Kerry postaram vídeos atacando o republicano George W. Bush no pleito de 2004; De Boer, Sütfeld e Groshek (2012), que identificaram vídeos de ataque em canais não oficiais no YouTube a vários candidatos do pleito presidencial de 2012, entre eles Barack Obama e Mitt Romney; Baumgartner (2013), o qual analisou a postagem de vídeos de humor contra esses dois candidatos também no YouTube em 2012; e Mejova, Srinivasan e Boynton (2013), que concluíram que a negatividade deu a tônica dos tweets sobre pré-candidatos republicanos a presidente em 2011

Outras pesquisas recentes também citam a ação de grupos não oficiais em pleitos norte-americanos na internet, como as de Alcott e Gentzkow (2017) e Persily (2017), 
porém esses estudos têm como foco a difusão de fake news ${ }^{3}$ no pleito norte-americano de 2016, sem correlacioná-las diretamente à questão da campanha negativa, fugindo, portanto, ao foco desta pesquisa.

Porém, é importante perceber que esse fenômeno guarda relação com a modificação no polo produtor de campanha negativa, pois, historicamente, a veiculação de ataques aos adversários era concentrada na comunicação oficial de candidatos e partidos, o que os inibia razoavelmente de produzir notícias falsas contra os rivais. Quando grupos não oficiais assumem a produção de campanha negativa, a criação de fake news passa a não sofrer os mesmos riscos, já que não se consegue comprovar facilmente a ligação desses agrupamentos às coligações oficiais (FERREIRA, 2018; PERSILY, 2017).

\section{Contextualização e metodologia}

A campanha para a Prefeitura do Rio de Janeiro, em 2016, foi a primeira depois da aprovação da reforma política de 2015, que determinou a redução do tempo de campanha no $1^{\circ}$ turno para apenas 45 dias (metade do anterior), ampliando a importância das campanhas online (POZOBON \& RIBEIRO, 2017).

Onze candidatos concorreram ao cargo, dos quais o então senador Marcelo Crivella e o à época deputado estadual Marcelo Freixo se habilitaram para o $2^{\circ}$ turno, com 27,7\% e 18,2\% dos votos válidos, respectivamente. A etapa final da sucessão foi caracterizada por ataques mútuos entre as candidaturas e seus militantes, sendo identificado até o uso de robôs para a disseminação de fake news nas mídias sociais (ÁRNAUDO, 2017).

O Rio foi a maior capital do País a ter $2^{\circ}$ turno naquele ano, o que introduziu na disputa um certo apelo nacional, mobilizando partidários e simpatizantes de diversas partes do Brasil. Ao fim do pleito, Crivella foi eleito com mais de 536 mil votos (59,3\%) em relação a Freixo (40,6\%).

Para estudar este cenário empiricamente, utilizamos procedimentos da Análise de Redes Sociais (ARS) (RIEDER \& ROHLE, 2012) para investigar as redes de campanha no Twitter. Foi utilizada a Search API4 do Twitter por meio do pacote twitte $R$ da linguagem $R$ para coletar tweets com as palavras Freixo, Crivella e as hashtags \#Freixo50, \#Crivella10 e \#ForaFreixo ao longo do $2^{\circ}$ turno do pleito carioca. A extração resultou em um banco de 530 mil tweets postados entre 6 e 30 de outubro de 2016.

Todavia, o volume total de tweets contempla diversos tipos de mensagens, desde publicações dos candidatos e da imprensa até comentários dos usuários, enquanto nosso foco é identificar apenas as publicações que possam ser caracterizadas como campanha negativa não oficial. Aplicamos então a análise de conteúdo (KRIPPENDORF, 2005)

3 Alcott e Gentzkow (2017) definem fake news como "artigos de notícias que são intencionalmente e verificadamente falsos".

4 A Search API do Twitter é um canal de extração de dados que viabiliza a coleta de tweets que mencionam um conjunto de termos retroativos a até sete dias do momento da coleta. 
manual para analisar as hashtags encontradas na amostra, e a estatística descritiva, com tabulações cruzadas, totais e médias, para responder às seguintes questões:

\section{QP1 - Como identificar as características da campanha negativa não oficial no Twitter?}

Os artigos relacionados não sugerem uma forma de identificar empiricamente as estratégias negativas não oficiais no Twitter. A própria informalidade das práticas que tangenciam os partidos oferecem desafios centrais para a operacionalização do conceito. Como evitar de considerar como campanha negativa críticas isoladas dos usuários, inclusive de jornalistas e cientistas políticos? Recuero et al. (2015) demonstraram que, entre as funções das hashtags, está a de marcar posicionamentos panfletários de suporte ou de oposição a pautas e lideranças. Outro marcador relevante de ataque não oficial é o uso de retweets e menções, pois essas conexões ajudam a criar redes de campanha para ataque e defesa de candidatos (ALVES, 2017b). Com base nesses indicadores da literatura, chega-se à hipótese única deste artigo:

H1: A campanha negativa não oficial no Twitter é construída por atores que não estão ligados oficialmente à candidatura, que citam ou retuitam, ao menos uma vez, outros perfis não oficiais da mesma rede de ataque, com o uso de hashtags para orientar os ataques.

Assim, considerou-se os seguintes indicadores:

- Hashtags: indica posicionamento panfletário de suporte ou oposição e evita confundir usuários engajados em campanha negativa não oficial com jornalistas e especialistas, já que estes tendem a não usar hashtags de ataque (ENLI \& SIMONSEN, 2018);

- Retweets e menções a outros atores da rede: indica engajamento na formação de redes de ataque, ou seja, dinâmicas de articulação de coletividades de perfis que se envolvem na desconstrução de candidaturas de adversários (ALVES, 2017b).

Para selecionar apenas mensagens de ataque, listamos todas as hashtags utilizadas no banco de dados e utilizamos uma Análise de Conteúdo manual (KRIPPENDORF, 2005) exclusiva dessas tags para identificar aquelas que caracterizam campanha negativa contra um dos candidatos, na medida em que esses termos, quando negativos, associam os candidatos a repercussões prejudiciais. A categorização consistiu em uma variável única dummy para aferir se as hashtags da amostra inicial eram ou não de ataque e foi feita em conjunto pelos autores deste trabalho, resultando nos termos:

- \#forafreixo

- \#nãofogedodebatecrivella

○ \#freixonão 


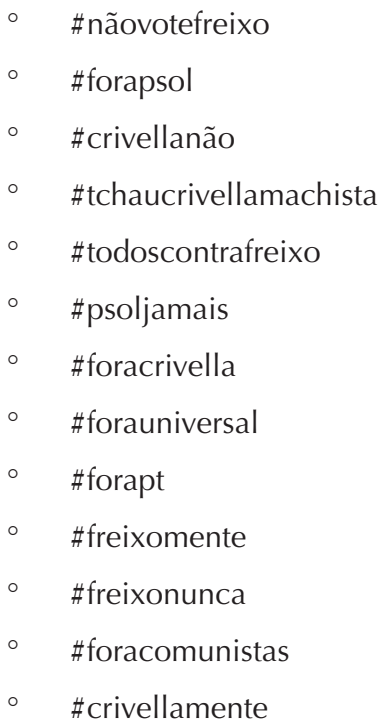

Finalmente, excluíram-se publicações e retweets das contas oficiais dos candidatos e partidos, já que elas são referentes à campanha oficial e não se adequam ao objeto desta pesquisa, resultando em uma amostra final de 11.407 tweets. Os dados obtidos serão expostos e analisados após a seção metodológica.

\section{QP2 - Qual a estrutura topológica das redes que atacam os candidatos nesta mídia social?}

A campanha digital imbrica atividades complementares de ataque, com funções diferentes para as estratégias dos candidatos e não oficiais. A fim de encontrar as "redes de ataque", aplicamos o método de ARS para descrever e analisar as ligações topológicas de redes nas mídias sociais (RECUERO, 2014).

Por meio do software Gephi, criamos redes em que os nós (pontos) são os perfis e as ligações (arestas) são a menção, retweet ou respostas contidas nas mensagens dos tweets de campanha negativa não oficial, classificados pelo método descrito na QP1. O desenho da rede foi elaborado pelo algoritmo Force Atlas 2, comumente aplicado para desenhar topologias de polarização online (RECUERO, 2014).

A identificação dos clusters foi feita por meio de uma métrica de ARS que divide a amostra em subgrupos de acordo com a densidade de suas ligações por meio do algoritmo de Louvain do Gephi. A clusterização está baseada no princípio na homofilia ideológica, na qual, de forma agregada, os perfis vão se conectar preferencialmente a pares com ideias e valores similares (BARBERÁ, 2015). Estes subgrupos configuram as redes de produtores e propagadores de campanha negativa não oficial. 
Com a finalidade de analisar as características topológicas das redes de disseminação de campanha negativa não oficial, aplicamos as seguintes métricas:

a. Grau de entrada: contagem simples das arestas que apontam em direção aos nós. Nesse estudo, as arestas são menções ou retweets, que indicam a popularidade das mensagens na rede (RECUERO, 2014);

b. Algoritmo de modularidade: técnica de segmentação das redes que utiliza estatísticas de identificação de comunidades baseada na densidade da ligação de subgrupos (BLONDEL et al, 2008).

\section{QP3 - Como podem ser caracterizados os principais perfis que veicularam campanha negativa não oficial no Twitter durante o período analisado?}

Para investigar as características dos atores que atuam no Twitter em redes de ataque, esse estudo utiliza duas medidas de análise de práticas comunicativas no microblog (BRUNS \& STIEGLITZ, 2013):

a. Publicações: medida referente ao total de tweets classificados como campanha negativa não oficial por perfis identificados durante o $2^{\circ}$ turno da disputa. Indica o grau de envolvimento nos ataques. Para comparar os usuários, aplicamos medidas estatísticas de posição. Perfis com volume de tweets negativos maior do que a média geral da amostra apontam para ataques mais sistematizados, enquanto um número de ataques por perfil abaixo da média indica baixa frequência de campanha negativa;

b. Disseminação e visibilidade: o total de retweets recebidos por ataque indica o grau de circulação das mensagens de campanha negativas na respectiva rede de ataque; e a somatória de seguidores do perfil no Twitter indica o alcance potencial de suas publicações.

Para operacionalizar a verificação das métricas propostas, elaboramos um script de análise no R, cujos resultados serão apresentados a seguir.

\section{Apresentação dos resultados}

A identificação das práticas de campanha negativa não oficial foi realizada a partir da Análise de Conteúdo manual das hashtags de ataque contra os principais candidatos, excluindo-se as mensagens tuitadas em suas contas oficiais e de partidos, bem como tweets de usuários isolados da rede, ou seja, que não retuitaram, mencionaram ou responderam a nenhum dos demais usuários do mesmo grupo de ataque. Nesse sentido, a codificação identificou 11.407 tweets que atendem a esses critérios, publicados por 1.749 perfis únicos. 
O Gráfico 1 (abaixo) indica a variação dos tweets de campanha negativa não oficial ao longo do período de análise.

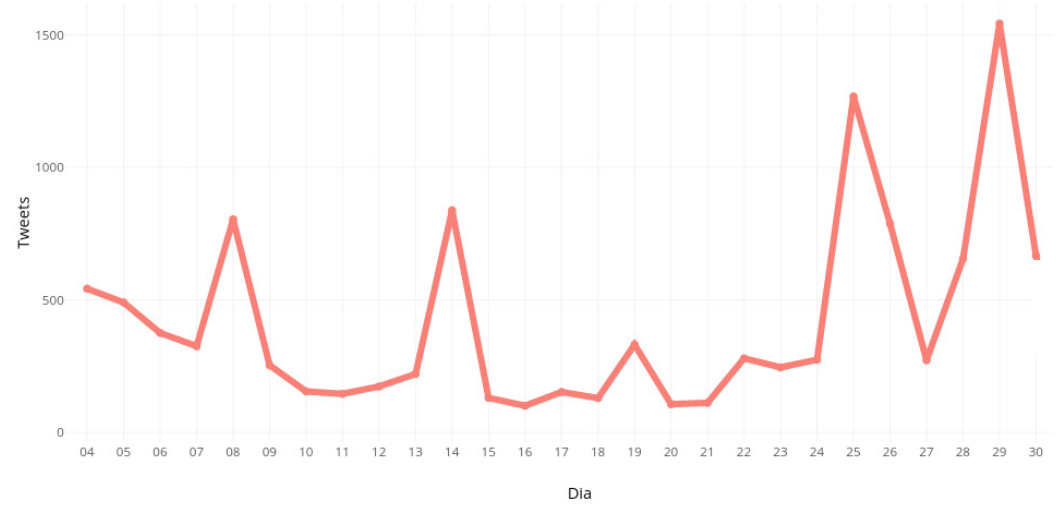

Gráf. 1. Número diário de tweets de campanha negativa não oficial Fonte: Os autores

Como se pode perceber do gráfico, houve quatro picos de publicação de ataques:

» $8 / 10$ - primeiro debate do $2^{\circ}$ turno, promovido na noite anterior pela TV Band/RJ;

» 14/10 - nesse dia foram divulgados os resultados de pesquisa eleitoral do Datafolha. Também estava previsto o debate do SBT Rio, que acabou não acontecendo devido à desistência de Crivella. Freixo chama a militância para o tuitaço \#NãoFogedoDebateCrivella, uma convocação a militantes para usarem essa hashtag no Twitter e, assim, dar visibilidade ao assunto;

» 25/10 - Sabatina com Crivella no telejornal RJTV da Globo Rio não é realizada pelo não comparecimento do candidato;

» 29/10 - debate da Globo ocorrido no dia 28 à noite.

Esses dados estão alinhados a uma das características da campanha negativa tradicional: a influência da campanha eleitoral na TV na decisão de atacar (BORBA, 2012).

Para analisar as características topológicas das redes de ataque, aplicamos a técnica de identificação de comunidades da ARS, que segmenta as conexões a partir da densidade, ou seja, busca apontar a formação de grupos que se retuitam e se mencionam com mais frequência.

O método de particionamento de redes, que produz uma resolução que busca afastar os nós e aproximar as ligações, encontrou duas comunidades, em verde e laranja 
na imagem plotada pelo algoritmo Force Atlas $2^{5}$ (Figura 1). Os rótulos são perfis do Twitter e seu tamanho demonstra o número de ligações recebidas na rede durante o período de análise, isto é, total de retweets e menções daquela conta ao realizar o ataque. O cluster verde é a rede Crivella, pois agrega perfis que atacaram o concorrente do PSOL. Por sua vez, o cluster laranja é a rede Freixo, composta de perfis que fizeram campanha contra o candidato do PRB.

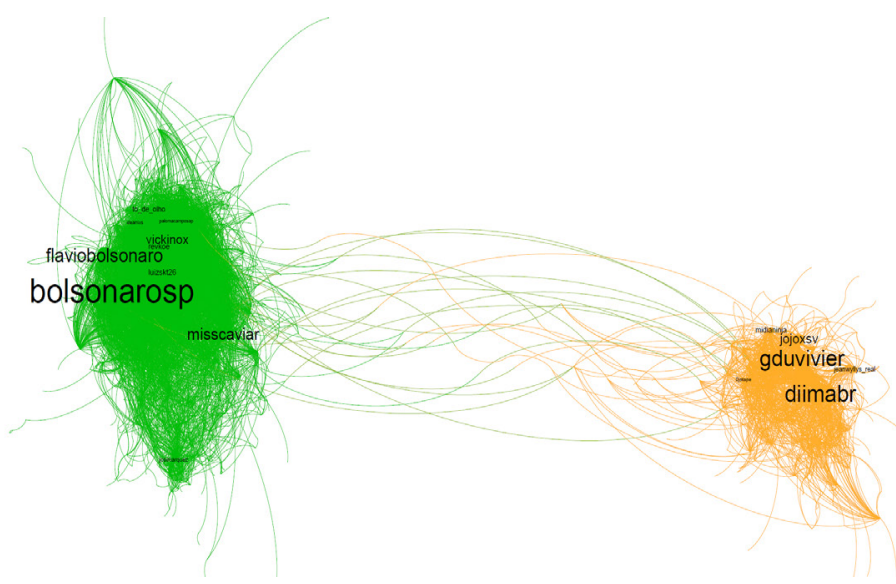

Fig.1. Representação dos clusters de Crivella e Freixo Fonte: Os autores

Este resultado demonstra que as redes de ataque são polarizadas, pois há pouquíssimas ligações estruturais entre os dois grupos, ou seja, há poucas interações entre grupos opostos. Além disso, indica a atuação de redes que vão além das chapas e dos apoios oficiais, na medida em que a família Bolsonaro, que teve seu candidato Flávio Bolsonaro (PSC-RJ) derrotado no primeiro turno, postou sistematicamente ataques no Twitter contra Freixo na segunda etapa da disputa.

O Gráfico 2 apresenta as 10 hashtags mais usadas nos tweets de cada cluster. As hashtags mais frequentes são: \#ForaFreixo, publicada 7.583 vezes, foi a principal contra o candidato psolista; \#nãofogedodebateCrivella, a mais usada na rede Freixo, refere-se às ausências do concorrente em sabatinas e debates na TV. As hashtags possuem funções de posicionamento e expressão, pois completam a produção de sentido no microblog.

5 Usamos os seguintes parâmetros: Dimensionamento = 1000, tamanho dos nós seguindo o grau de entrada, isto é, total de menções ou RTs recebidos pela conta. 


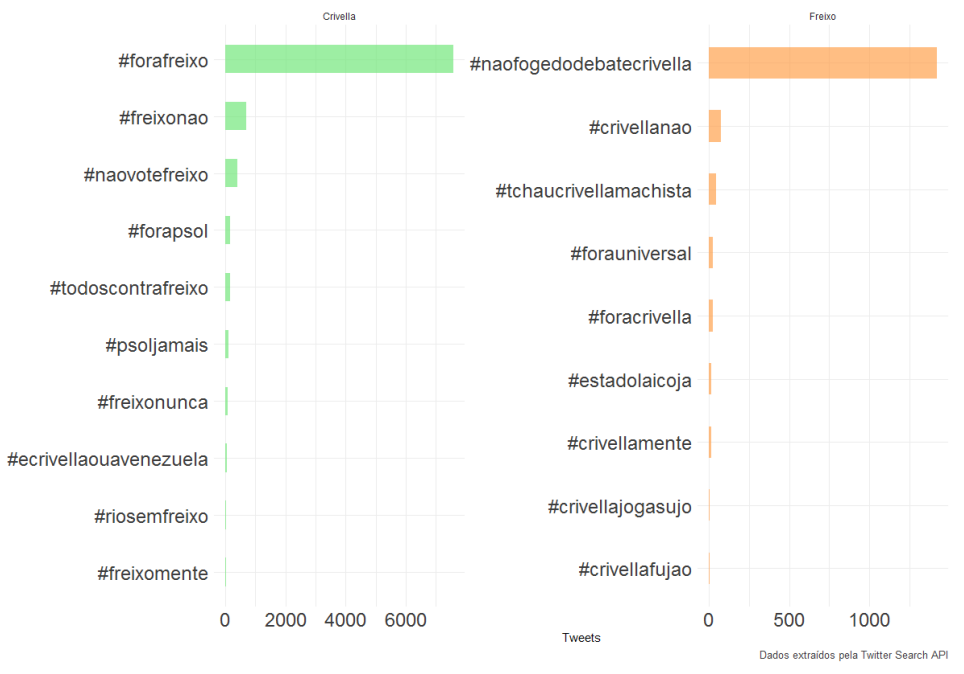

Gráf. 2. Hahstags mais frequentes em cada cluster. Fonte: Os autores

Para analisar as características dos usuários que produzem campanha negativa não oficial no Twitter, estudamos dois aspectos do engajamento deles na estratégia: a quantidade de mensagens de ataque publicadas, indicando o envolvimento e o nível de sistematização, e o alcance dos tweets, que indicam o papel de cada perfil na rede.

Em seguida, dividimos os perfis entre aqueles acima e abaixo da média de seguidores $(3.559,3)$ e de ataques por usuário (5,3). Assim, contas com mais de 3.599,3 seguidores foram consideradas populares e com mais de 5,3, com muitos ataques.

O resultado da relação entre a quantidade de ataques e sua base de seguidores está na Tabela 1 (abaixo).

\begin{tabular}{|c|c|c|c|}
\hline Categoria & Poucos Seguidores & Muitos Seguidores & Total \\
\hline Poucos Ataques & $1.277(73,01 \%)$ & $125(7,16 \%)$ & $1.402(80,17 \%)$ \\
\hline Muitos Ataques & $302(17,26 \%)$ & $45(2,57 \%)$ & $347(19,83 \%)$ \\
\hline
\end{tabular}

Tab. 1. Classificação dos perfis em relação à campanha negativa não oficial. Fonte: Os autores

A maior parte dos perfis que praticam campanha negativa no Twitter possui menos de 3.559 seguidores e faz até cinco ataques. No entanto, 17,26\% dos usuários atacam os candidatos com frequência superior à média da amostra. Uma parcela destes chega 
a ter centenas de tweets no período, o que demonstra a sistematização da produção de conteúdos de propaganda negativa, bem como o engajamento desses usuários na disseminação dessas mensagens. Um dos usuários, por exemplo, tuitou 354 ataques no $2^{\circ}$ turno, o que representa frequência diária superior a 10.

Entre os usuários que aderem às hashtags de campanha negativa, 80\% publicam até cinco mensagens de ataque de 6 a 30 de outubro de 2016, ou seja, se enquadram entre os perfis que postaram "poucos ataques". Por outro lado, quase $20 \%$ praticam ataques de forma sistematizada (acima da média da amostra), sugerindo um envolvimento dedicado à desconstrução de oponentes. Nesse sentido, podemos classificar os perfis que postaram tweets de campanha negativa conforme suas respectivas funções nas redes de ataque, conforme os dados da Tabela 1:

1. disseminadores: são perfis bastante envolvidos na produção de ataques com número de mensagens postadas acima da média da amostra, porém com baixo alcance . Atuam em conjunto com outros usuários, aderindo a hashtags, e têm o papel de disseminadores de perfis com maior visibilidade;

2. influenciadores: perfis que postam poucos ataques, porém apresentam grande influência na rede, pois, por terem centenas de milhares de seguidores, suas mensagens são bastante retuitadas.

Cabe salientar que essas duas funções não se sobrepõem, pois nenhum perfil incluído na amostra tuitou mais de 25 ataques e tem milhares de seguidores. Exemplos interessantes são os dos então deputados federais Marco Feliciano (PSC-SP) e Jean Wyllys (PSOL-RJ), que eram seguidos por mais de 400 mil usuários e atacaram uma e duas vezes, respectivamente (figura 2) no período analisado, porém com grande quantidade de RTs.

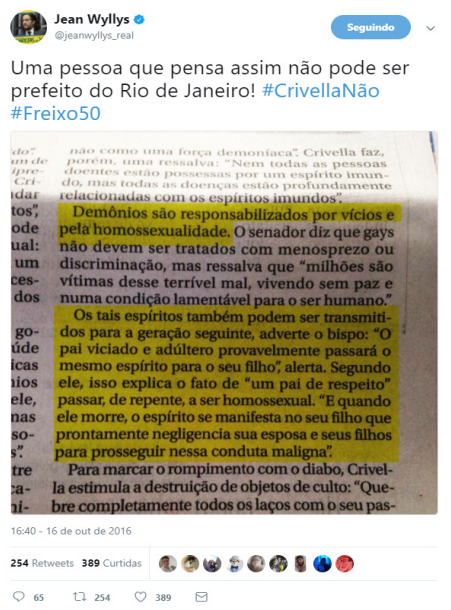

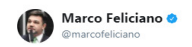

Que o RJ não caia nas lábias de um psolista. Não há nada pior do que um comunista travestido de bom moço progressista. \#forafreixo

$15: 48-7$ de out de 2016

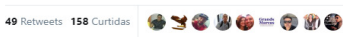

$10 \quad 07290158$

Fig. 2. Tweets de perfis influenciadores que fizeram campanha negativa. Fonte: Os autores 
O grupo de perfis mais retuitados inclui usuários comuns com alto engajamento no Twitter e celebridades midiáticas, como o humorista Gregório Duvivier e o perfil satírico Dilma Bolada, e detentores de cargos políticos que não concorriam à eleição no $2^{\circ}$ turno, como Wyllys e Flávio Bolsonaro. A rede de ataque de Crivella tem a participação frequente de políticos da família Bolsonaro, além de representantes e membros da igreja evangélica. Por sua vez, Freixo foi apoiado por movimentos sociais, meios de comunicação vinculados ao campo progressista, como a Mídia Ninja, ativistas de esquerda e militantes dos direitos civis e dos LGBTs.

Os dados apresentados permitem concluir pela procedência da $\mathrm{H} 1$, ou seja, a campanha negativa não oficial no Twitter nas eleições municipais do Rio em 2016 teve, sim, a participação de atores não ligados oficialmente aos candidatos e partidos, os quais usaram hashtags de ataque a seus opositores e que citaram ou retuitaram, ao menos uma vez, outros perfis não oficiais da mesma rede de ataque.

Os dados também mostram a manutenção de outras características da campanha negativa tradicional: (1) a agenda midiática influencia na decisão de quando atacar - dias de debates e entrevistas dos candidatos na televisão registraram o maior volume de campanha negativa não oficial; (2) a quantidade de ataques cresce com a proximidade da eleição; (3) os uso dos contra-ataques como resposta a mensagens negativas recebidas da rede rival; (4) a desqualificação, por parte da rede não oficial, de apoios recebidos pelo oponente - um exemplo foi o uso da hashtag \#forapt por apoiadores de Crivella, associando-a ao nome de Freixo, com base no apoio do PT ao candidato socialista; (5) o apoio de militantes para divulgar informações negativas sobre o concorrente (ANSOLABEHERE \& IYENGAR, 1995; BORBA, 2012). Esses pontos de convergência entre as características clássicas de campanha negativa e a atuação das redes não oficiais no Twitter reforçam a ideia de que o fenômeno está se reconfigurando e que não apenas as coligações oficiais criaram e distribuíram conteúdo negativo sobre os adversários eleitorais.

\section{Discussão dos resultados e considerações finais}

Este artigo visou investigar a promoção de campanha negativa não oficial no Twitter durante o $2^{\circ}$ turno da disputa pela Prefeitura do Rio de Janeiro em 2016. Analisou-se a promoção de ataques no Twitter por perfis não oficialmente ligados aos candidatos Marcello Crivella e Marcelo Freixo ou a seus partidos. A pesquisa contribui teoricamente para o campo da Comunicação e Política ao descrever e analisar empiricamente uma estratégia de comunicação eleitoral adotada por grupos de agentes não diretamente ligados às coligações os quais disseminam sistematicamente conteúdo contra os candidatos, ampliando o escopo de análise das estratégias de comunicação eleitoral para diferentes produtores de informação política.

A QP1 indagou como identificar as características da promoção de campanha negativa não oficial. O estudo confirmou que as redes não diretamente ligadas 
aos candidatos desempenharam papel importante na disputa. Entre 6 e 30 de outubro de 2016, 11.407 tweets de ataque oriundos de perfis que não são de partidos e/ou dos candidatos foram identificados.

A análise observou o uso sistemático de hashtags de ataque contra os dois candidatos, o que é uma característica de campanha negativa. A presença desses termos para identificar a propaganda negativa é autoexplicativa em muitos casos, caso das tags \#forafreixo e \#nãofogedodebateCrivella, pois a promoção de uma comunicação que visa prejudicar a imagem do candidato oponente, pressuposto básico do conceito original, também está presente nos ataques publicados por redes não oficiais. Além disso, a utilização desse recurso permite diferenciar ataques de usuários a candidatos de críticas de jornalistas ou cientistas políticos, já que estes profissionais não costumam usar tags negativas.

A proposta metodológica considerou somente perfis que criam conexões estruturais da rede por meio de menções e retweets, o que contribuiu para apontar a atuação de redes de ataque não oficial contra os candidatos.

Por sua vez, a QP2 indagou quais foram as estruturas topológicas das redes de ataque aos candidatos na eleição para prefeito do Rio em 2016. A análise dos clusters permitiu identificar duas redes principais, de ataque a cada um dos candidatos, respectivamente. Ambas são muito ligadas entre si, mas apresentam poucas interações com a rede rival, mostrando um comportamento extremamente polarizado. A diferença no uso das hashtags mais frequentes por cada grupo ajudou a comprovar essa polarização, bem como a pouca existência de ligações entre as duas comunidades.

No que tange à QP3, a maioria dos ataques é proveniente de militantes e usuários anônimos, ao passo que representantes políticos ou midiáticos e celebridades digitais compõem uma pequena parcela dos perfis que tuitam mensagens de campanha negativa. Neste último grupo, por ter milhares de seguidores, estavam os usuários com o maior número de retweets.

Assim, chega-se à conclusão que há dois grupos específicos que atuam na promoção de campanha negativa não oficial no Twitter: os influenciadores, que incluem políticos e celebridades midiáticas e digitais, os quais postam poucas mensagens negativas, mas que são largamente difundidas; e os disseminadores, composto por militantes e usuários comuns que postam um volume grande de tweets contra o adversário e retuitam as mensagens postadas pelos usuários de maior influência.

Uma hipótese que explica esse cenário é o objetivo desses usuários de auxiliarem os candidatos de sua preferência, pois, ao difundir mensagens negativas sobre os concorrentes, diminuem a necessidade de o político apoiado ter de atacar com maior frequência, o que poderia gerar a este o risco do efeito bumerangue ou de eventuais punições pelo Tribunal Regional Eleitoral.

Essas respostas permitiram, então, validar a H1, pois a campanha negativa não oficial no Twitter na disputa pela Prefeitura do Rio de Janeiro em 2016 foi caracterizada 
pela participação de atores não ligados oficialmente a candidaturas e partidos, os quais usaram hashtags de ataque ao candidato adversário e citaram ou retuitaram outros perfis não oficiais da mesma rede de ataque.

Para além das oportunidades que a pesquisa sobre a campanha negativa não oficial em mídias sociais como o Twitter oferece - por exemplo, a coincidência de características em relação ao conceito original, o qual tem candidatos e partidos como pólos únicos de produção de mensagens -, é preciso também reconhecer que há limitações a serem superadas no futuro, considerando a originalidade deste trabalho. É preciso investigar a ligação que grupos supostamente "independentes" tenham com legendas e candidatos. O exemplo do Movimento Brasil Livre (MBL), que defendeu o impeachment de Dilma Rousseff em 2016 apresentando-se como independente e, posteriormente, descobriu-se ter sido financiado por partidos, exemplifica isso ${ }^{6}$.

Outra limitação é sobre o grau de influência dos bots na campanha negativa não oficial, o que demandaria investigação específica, pois, caso expressivo, poderia levar a concluir que parte das mensagens tuitadas durante as campanhas pode ser proveniente de perfis falsos, os quais, caso tenham ligação oculta com partidos e candidatos, integrariam uma campanha "oficial disfarçada".

Cabe reconhecer ainda que o uso da análise exploratória por meio de hashtags para identificar a campanha negativa não oficial pode não detectar posts contendo ironias e ambiguidades. Esse talvez tenha sido o caso de parte dos tweets com a expressão \#foraglobo, a segunda mais presente em nosso corpus inicial, mas não incluída na amostra final por não apresentar, por si só, conteúdo negativo contra um ou outro candidato.

A ausência de tweets do pastor Silas Malafaia no corpus de análise também é um exemplo da necessidade de aprimorar a metodologia aqui sugerida, pois este não fez parte da amostra por não usar hashtags no período analisado, apesar de ter atacado sistematicamente Freixo durante o pleito. Pesquisas futuras podem aprimorar técnicas de identificação da campanha negativa não oficial nesse tipo de post.

É importante também investigar o fenômeno no Facebook, devido à liderança no número de usuários que esta rede detém no Brasil desde 2011, e no WhatsApp, considerando o papel decisivo que o aplicativo de comunicação instantânea desempenhou nas eleições presidenciais de 2018 (RESENDE et al, 2019).

Por fim, é preciso também discutir a reconfiguração desse fenômeno a partir da relação entre a atuação dos grupos não oficiais e a disseminação de fake news, tendo em vista a importância que esse fenômeno teve nas eleições dos Estados Unidos de 2016 e na eleição presidencial brasileira de 2018 (FERREIRA, 2018; RESENDE et al, 2019).

6 Ver http://noticias.uol.com.br/politica/ultimas-noticias/2016/05/27/maquina-de-partidos-foi-utilizada-em-atospro-impeachment-diz-lider-do-mbl.htm (acesso em 17/09/2017). 
Ícaro Joathan e Marcelo Alves são doutorandos no Programa de Pós-graduação em Comunicação da Universidade Federal Fluminense (UFF). O primeiro é bolsista de doutorado da Fundação Cearense de Apoio ao Desenvolvimento Tecnológico (Funcap); o segundo é bolsista de doutorado da Coordenação de Aperfeiçoamento de Pessoal de Nível Superior (Capes).

icarojoathan@gmail.com

marcelo.alves.ufsj@hotmail.com

\section{Referências}

ALLCOTT, H. \& GENTZKOW, M. Social Media and Fake News in the 2016 Election. Journal of Economic Perspectives, v. 31, n. 2, p. 211-236, 2017.

ALVES, M. Campanha não oficial-A Rede Antipetista na eleição de 2014. Fronteiras-estudos midiáticos, v. 19, n. 1, p. 102-119, 2017 a. $120,2017 b$

Redes de campanha na eleição do Rio de Janeiro em 2016. Compolítica, v. 7, n. 2, p. 87-

ANSOLABEHERE, S. \& IYENGAR, S. Going negative: How attack ads shrink and polarize the electorate. New York: The Free Press, 1995.

ÁRNAUDO, D. Computational Propaganda in Brazil: Social Bots during Elections. In: WOOLEY, S. \& HOWARD, P. Project on Computational Propaganda 2017.8. Oxford, 2017.

BARBERÁ, P. Birds of the same feather tweet together: Bayesian ideal point estimation using Twitter data. Political Analysis, v. 23, n. 1, p. 76-91, 2015.

BAUMGARTNER, J. Internet political ads in 2012: can humor mitigate unintended effects of negative campaigning? Social Science Computer Review, v.31, n.5, p. 601-613, 2013.

BLONDEL, V. D.; GUILLAUME, J. L.; LAMBIOTTE, R.; LEFEBVRE, E. Fast unfolding of communities in large networks. Journal of statistical mechanics, v. 2008, n. 10, p. 1-12, 2008.

BORBA, F. A propaganda negativa: estratégia e voto nas eleições brasileiras. Tese (Doutorado em Ciência Política) - Universidade do Estado do Rio de Janeiro, 2012.

BRUNS, A. \& STIEGLITZ, S. Towards more systematic Twitter analysis: metrics for tweeting activities. International journal of social research methodology, v. 16, n. 2, p. 91-108, 2013.

CERVI, E. \& MASSUCHIN, M. O Uso do Twitter nas Eleições de 2010: o microblog nas campanhas dos principais candidatos ao governo do Paraná. Contemporânea, Salvador, v.9, n.2, p. 319-334, 2011.

CHAIA, V. Internet e eleições: as comunidades políticas no Orkut nas eleições de 2006. Logos, Rio de Janeiro, n. 27, p. 127-140, 2007.

CHENG, H. \& RIFFE, D. Attention, perception, and perceived effects: negative political advertising in a battleground state of the 2004 presidential election. Mass Communication and Society, Philadelphia, v. 11, n. 2, p. 177-196, 2008. 
DALTON, P. \& MCILWAIN, C. Third-Party "Hatchet" Ads: An Exploratory Content Study Comparing Third-Party and Candidate Spots From the 2004 Presidential Election. Atlantic Journal of Communication, Philadelphia, v. 19, n. 3, p. 129-151, 2011.

DE BOER, N.; SÜTFELD, H.; GROSHEK, J. Social media and personal attacks: A comparative perspective on co-creation and political advertising in presidential campaigns on YouTube. First Monday, Bridgman, v. 17, n. 3, p. 1-16, 2012.

DEVLIN, P. Contrasts in presidential campaign commercials of 2004-2005. American Behavioral Scientist, Arizona, v. 49, n. 2, p. 279-313, 2005.

DOWLING, C. M. \& WITCHOWSKY, A. Attacks without Consequence? Candidates, Parties, Groups, and the Changing Face of Negative Advertising. American Journal of Political Science, v. 59, n. 1, p. 19-36, 2015.

ENLI, G. \& SIMONSEN, C. 'Social media logic' meets professional norms: Twitter hashtags usage by journalists and politicians. Information, Communication \& Society, York, v. 21, n. 8, p. 1081-1096, 2018.

FERREIRA, R. Rede de mentiras: a propagação de fake news na pré-campanha presidencial brasileira. Observatorio (OBS*), edição especial, p. 139-162, 2018.

GARRAMONE, G. Effects of Negative Political Advertising: The Roles of Sponsor and Rebuttal. Journal of Broadcasting and Electronic Media, v. 29, n. 2, p. 147-159, 1985.

JOATHAN, Í. \& MARQUES, F. P. J. Campanha negativa e formas de uso do Facebook nas eleições presidenciais brasileiras de 2014. In: MOREIRA, A.; ARAÚJO, E.; SOUSA, H. (Eds.). Comunicação e Política: tempos, contextos e desafios, Braga: CECS, 2017.

KRIPPENDORFF, K. Content analysis: an introduction to its methodology. Sage: Thousand Oaks, 2005.

MEJOVA; Y.; SRINIVASAN, P.; BOYNTON, B. GOP Primary Season on Twitter: "Popular" Political Sentiment in Social Media. In: INTERNATIONAL CONFERENCE ON WEB SEARCH AND DATA MINING, 6., 4 a 8 fev. 2013, Roma. Anais... Roma: ACM, 2013.

MEIRICK, P. C. Political Knowledge and Sponsorship in Backlash from Party-and Candidate-sponsored Attacks, Communication Reports, v. 18, n, 1-2, p. 75-84, 2005.

MILLER, K. The Divided Labor of Attack Advertising in Congressional Campaigns. In: MPSA ANNUAL MEETING, 74., 7 a 10 abr. 2016, Chicago. Anais... Chicago: MPSA, 2016.

MOMOC, A. Online negative campaign in the 2004 Romanian presidential election. Styles of Communication, v. 2, n. 1, p. 89-99, 2010.

MOURA, M. \& MICHELSON, M. R. WhatsApp in Brazil: mobilising voters through door-to-door and personal messages. Internet Policy Review, v. 6, n. 4, p. 1-18, 2017.

PERSILY, N. The 2016 U.S. Election: can democracy survive the internet? Journal of Democracy, V. 28, n. 2, p. 63-76, 2017.

POZOBON, R. \& RIBEIRO, A. Freixo Prefeito: potencialidades da ambiência digital na publicização da campanha eleitoral de 2016. Mediação, v. 19, n. 24, p. 103-126, 2017.

QUELER, J. Quando o eleitor faz a propaganda política: o engajamento popular na campanha eleitoral de Jânio Quadros. Revista Tempo, v. 14, n. 28, p. 59-84, 2010.

RECUERO, R. Contribuições da Análise de Redes Sociais para o estudo das redes sociais na Internet: o caso da hashtag\# Tamojuntodilma e\# CalaabocaDilma. Fronteiras-estudos midiáticos, v. 16, n. 2, p. $60-77,2014$. 
RECUERO, R., ZAGO, G., BASTOS, M. T., ARAÚJO, R. Hashtags functions in the protests across Brazil. SAGE Open, v. 5, n. 2, p. 1-14, 2015.

RESENDE, G. et al. (Mis)Information Dissemination in WhatsApp: Gathering, Analyzing and Countermeasures. In: INTERNATIONAL WORLD WIDE WEB CONFERENCE COMMITTEE, 13 a 17 mai. 2019, San Francisco. Anais... San Francisco, IW3C2, 2019.

RIEDER, B. \& ROHLE, T. Digital Methods: Five Challenges, In: BERRY, D. Understanding Digital Humanities. Palgrave Macmillan: Basingstoke, 2012. 